\section{Acknowledgment}

I am grateful to Dr M. H. Oelbaum for permission to report this case, and the Department of Physical Medicine at Manchester Royal Infirmary for EMG studies.

\section{References}

Brain, W.R. \& WALton, J.N. (1969) Brain's Diseases of the Nervous System. 7th Edn, 781. Oxford University Press, London.
Brain, W.R., Wright, A.D. \& Wilkinson, M. (1947) Spontaneous compression of both median nerves in theD carpal tunnel. Lancet. i, 277.

Guly, P.J. (1959) Carpal tunnel syndrome. British MedicafJournal, 1, 1184.

WiLkinson, M. (1960) The carpal tunnel syndrome in pregnancy. Lancet, i, 453.

\title{
Naevus striatus unguis
}

\author{
K. LIDDELL \\ M.B., M.R.C.P. \\ M. D. Catterall \\ M.B., M.R.C.P.
}

\section{Department of Dermatology, Southampton University Hospitals}

\begin{abstract}
Summary
Three patients presented with an asymptomatic longitudinal pigmented band in a nail. A junctional melanocytic naevus in the nail matrix was suspected; this was confirmed by histological examination in each case. Differential diagnosis and management are discussed, together with a review of the literature. Local excision is considered to be the treatment of choice.
\end{abstract}

\section{Introduction}

A longitudinal pigmented band, presenting in the otherwise normal nail of a Caucasian patient is distinctly uncommon. Samman (1972) mentions the condition only briefly in Textbook of Dermatology and The Nails in Disease (Samman, 1965), and alludes to the cause as a junctional melanocytic naevus in the nail matrix. In view of its potential for malignant change, he prefers excision as the treatment of choice, after removal of the nail plate.

Pigmented bands in the nails of coloured patients are generally thought to be of less significance. The cases of two Caucasian patients who presented almost concurrently with this condition in a fingernail and a West Indian with the same clinical and histological findings in a toenail are now reported.

\section{Case histories}

\section{Case 1}

A 27-year-old Caucasian female presented with a longitudinal pigmented band in the left index fingernail (Fig. 1). It had been prominent for about 6 months, but apparently a faint yellowish browh $\vec{\theta}$ streak had been present for some time previous There was no history of trauma and the lesion was. totally asymptomatic. Her general health was goo $\overline{4}$. She was not on any medication and there was nothing of relevance in her family or past medical history.

On examination there was a narrow, brown longi- $\triangle$ tudinal band which appeared to emerge from the $\overrightarrow{\vec{O}}$ nail matrix and involved the full length and thickness 3 of the nail plate. No significant lymphadenopathy was detected and a diagnosis of junctional naevus of the nail of the matrix was made.

In view of the possibility of malignant change, it was decided to remove the nail plate and excise the $\frac{5}{3}$ matrix to include the suspected naevus. At operation, after avulsion of the nail, a small pigmented mark corresponding to the origin of the pigmented line, was found on the matrix. This was excised with a narrow margin and the defect sutured.

Histological examination revealed the presence of a small junctional melanocytic naevus.

\section{Case 2}

A 22-year-old Caucasian naval cook presented in $N$ 1972 with a dark brown, longitudinal band in his right thumbnail. This had appeared 2 years pre- 0 viously, apparently spontaneously, as he had no $\mathbb{D}$ recollection of preceding trauma. A dermatologist ? made a clinical diagnosis of "junctional naevus of the $\frac{T}{0}$ nail matrix' and advised periodic follow-up, but no 


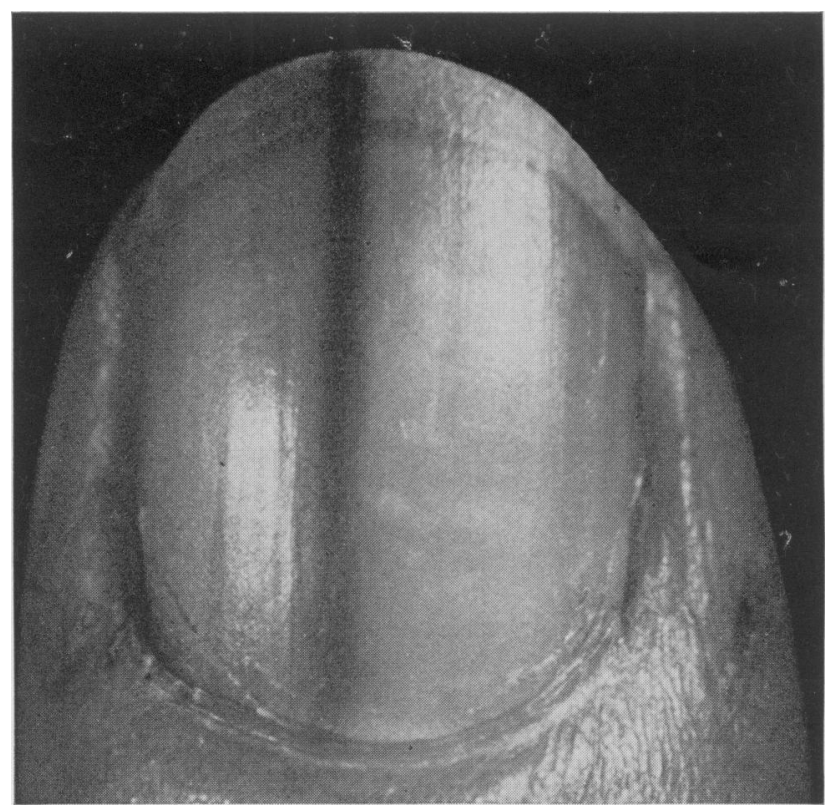

Fig. 1. Case 1.

active treatment. When the patient was reviewed towards the end of 1975 , the condition had apparently remained unchanged and on examination there was a broad, darkly pigmented band extending from the nail matrix to the free edge of the nail plate of the right thumbnail (Fig. 2). The band appeared to involve the whole thickness of the nail plate but the nail otherwise appeared to be normal and general examination was unremarkable. In view of the width of the band, it was decided to perform a Zadek's ablation of the nail, to include excision of the naevus. Following avulsion of the nail plate, exploration of the matrix and posterior nail fold failed to reveal a macroscopically evident lesion. Detailed histological examination of the specimen demonstrated the presence of a tiny junctional naevus.

\section{Case 3}

A 21-year-old West Indian girl presented with pruritus in the perineum and peri-anal warts. On routine examination she was found to have a $3 \mathrm{~mm}$ wide longitudinal brown line, extending the full length of the nail of the left great toe. According to her mother, this had been present since birth. It was totally asymptomatic, and had not increased in width relative to the nail.

The nail was subsequently avulsed, revealing a

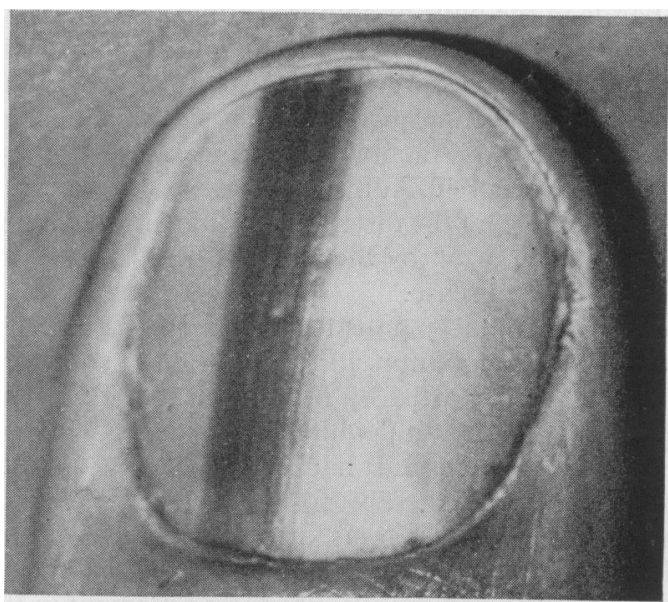

FIG. 2. Case 2.

naevus of benign appearance in the nail bed (Fig. 3), which was totally excised.

Histology confirmed a benign junctional naevus.

\section{Discussion}

The commonest cause of blackening of part of the nail is a subungual haemorrhage or haematoma. 


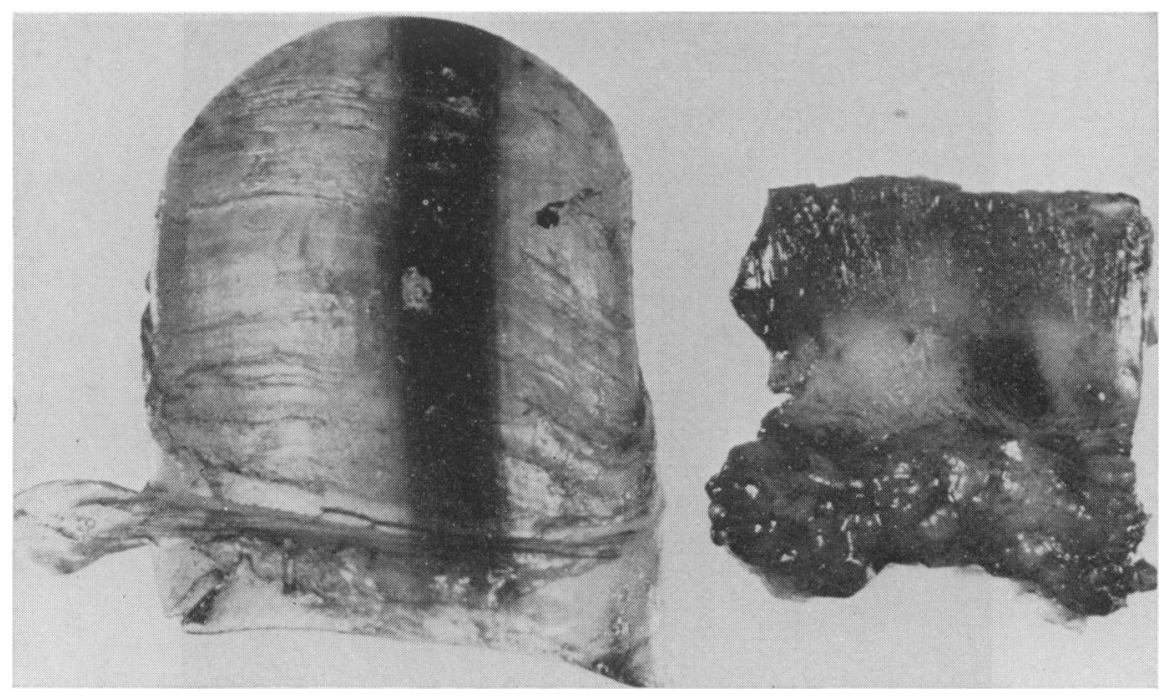

Fig. 3. Case 3 following surgery, to show the junctional naevus in the nail matrix.

Dark streaks in the nails are not uncommon in the coloured races and are thought by many authorities, to be the result of very minor trauma and of no undue significance, but Bisht and Singh (1962) attributed them to malnutrition in Indians. The pigment in bands in the nails of coloured subjects is melanin, arising from normally functioning melanocytes in the matrix and according to Pillsbury, Shelley and Kligman (1956), the pigmentation is always benign.

According to Allenby and Snell (1966), these bands can occur in Addison's disease. Brown nailbed arcs affecting the distal part of the fingernail bed have been reported by Stewart and Raffle (1972) in chronic renal disease.

A longitudinal pigmented band in the nail is certainly less common in white subjects and the first case was reported by Montgomery (1917), who described a 36-year-old white man with a pigmented line in one thumbnail. It had developed shortly after superficial X-ray therapy for eczema of his hands and although there was no histological proof, Montgomery felt that there was a pigmented naevus situated in the nail groove, producing pigment in the newly formed nail. The condition was described as 'naevus striatus symmetricus unguis' following case reports by Oppenheim and Cohen (1942) and Oliver and Bluefarb (1944). The potential gravity of a pigmented streak extending the length of the nail was illustrated by reports of malignant melanomata by Womack (1927), Engman, Mook and Engman (1931) and Pack and Adair (1939).

In 1952, Nobel, Ferrin, and Merandino reported an interesting case of a male white physician who, having had a brownish-black longitudinal hair-line stripe in the left fifth fingernail for about 4 years, $\stackrel{\mathbb{C}}{-}$ noticed a thin darker line developing within the original stripe. Probably prompted by the sudden $\frac{\text { th }}{2}$ crease in pigmentation, a decision was made amputate the terminal phalanx of the affected finger Histological examination showed a benign junctionab naevus of the nail matrix.

In 1960, Katherine Harvey reported the case of $\frac{0}{0}$ 39-year-old Hungarian female who had developec a pigmented longitudinal stripe 4 years previously, which had slowly extended laterally to involve the whole of the thumbnail, with the exception of a welf defined segment. The nail had recently cracked. longitudinally without any apparent precipitating trauma. Considering the report by Pack and Adait:(1939), in which they stated that a naevus should be regarded as clinically malignant when it breaksin through the nail plate, it was decided to amputate the terminal phalanx. Histological examination

The sparse literature to date, indicates that pig $\frac{D}{0}$ mented bands in the nails of white subjects are due to junctional melanocytic naevi or malignant melano- $N$ mata. The present three cases are examples of then former and the authors support local excision as the treatment of choice. Should the clinical picture ${ }^{\omega}$ suggest more sinister change, a frozen section could be examined before more radical surgery is under taken.

The fact that a solitary pigmented longitudina $\stackrel{5}{+}_{+}$ band in the nail of a coloured patient proved to be due to a junctional naevus suggests that the samed 
aetiology should be considered, irrespective of race. Multiple pigmented longitudinal bands in the nails of coloured patients may not have the same significance.

\section{Acknowledgments}

We wish to thank our colleagues in Surgery and Pathology for their help, and also Dr I. W. Caldwell and Dr J. E. White, for allowing us to report their patients.

\section{References}

Allenby, C.F., \& Snell, P.L. (1966) Longitudinal pigmentation of the nails in Addison's disease. British Medical Journal, 1, 1582.

Bisht, D.B. \& SiNGH, S.S. (1962) Pigmented bands on nails. A new sign of malnutrition. Lancet, $\mathbf{i}, 507$.

Engman, M.F., MooK, W.H. \& Engman, M.F., Jr (1931) Melanotic whitiow. Archives of Dermatology and Syphilology, 23, 1174.

HaRvey, K.M. (1960) Pigmented naevus of nail. Lancet, ii, 848.
Montgomery, D.W. (1917) A pigmented stripe in the thumb nail. Journal of Cutaneous Disease, 35, 99.

Nobel, J.F., Ferrin, A. \& Merandino, K.A., (1952) Pigmented naevus of the fingernail matrix. Archives of Dermatology and Syphilology, 65, 49.

Oliver, E.A. \& Bluefarb, S.M. (1944) Naevus striatus symmetricus unguis, Archives of Dermatology and Syphilo$\log y, 49,190$.

Oppenheim, M. \& Cohen, D. (1942) Naevus striatus symmetricus of the thumbs, Archives of Dermatology and Syphilology, 45, 253.

PACK, G.T. \& AdAIR, F.E. (1939) Subungual melanoma. Surgery, 5, 47.

Pillsbury, D.M., Shelley, W.B. \& Kligman, A.M. (1956) In: Dermatology. W. B. Saunders, Philadelphia, p. 1022.

Samman, P.D. (1965) The Nails in Disease (First Edition) p. 90, William Heinemann, London.

Samman, P.D. (1972) The Nails. In: Textbook of Dermatology (Ed. by A. J. Rook, D. S. Wilkinson \& F. J. Ebling), 2nd Edn, 2, 1657, Blackwell Scientific Publications, Oxford.

Stewart, W.K. \& Raffle, E.J., (1972) Brown nail-bed arcs and chronic renal disease, British Medical Journal. 1, 784.

Womack, N.A. (1927) Subungual melanoma. Archives of Surgery, 15, 667.

\title{
Hereditary angio-oedema with mesangiocapillary glomerulonephritis
}

\author{
JuAn Plaza \\ M.D.
}

\author{
Prida Malasit \\ M.D., M.R.C.P.
}

\author{
DAVID N. S. KERR \\ M.Sc., F.R.C.P. (Edin.), F.R.C.P. (Lond.) \\ University of Newcastle-upon-Tyne, England
}

\begin{abstract}
Summary
A patient with hereditary angio-oedema (HAO) developed mesangiocapillary glomerulonephritis (MCGN) under observation. HAO is characterized by an inherited defect of complement-deficiency of $\mathrm{C1}$ esterase. MCGN is often associated with another complement abnormality which leads to depression of serum $\mathrm{C} 3$ and there is some evidence that the complement abnormality precedes the nephritis. The coincidence of these two rare diseases in the present patient, and in one previously described, suggests that other complement abnormalities may predispose to the development of MCGN.
\end{abstract}

Correspondence: Professor D. N. S. Kerr, Department of Medicine, Royal Victoria Infirmary, Newcastle-upon-Tyne NE1 4LP.

\section{Introduction}

Hereditary angio-oedema (HAO) is a disease inherited as an autosomal dominant in which there is a deficiency of an inhibitor of the activated first component of complement ( $\mathrm{Cl}$ esterase inhibitor). It is characterized by attacks of oedema of the skin and mucous membranes which may be life-threatening when the pharynx and larynx are involved (Donaldson and Evans, 1963; Hadjiyannaki and Lachmann, 1971; Beck et al., 1973).

Mesangiocapillary glomerulonephritis (MCGN) is a form of chronic glomerulonephritis with mesangial hyperplasia and capillary wall thickening thought to arise from the deposition of immune complexes either under (subendothelial type) or within (dense deposit type) the basement 